\title{
The efficacy of community-based rehabilitation programmes for adults with $\mathrm{TBI}$
}

Lizzie Evans, Claire Brewis

Aims: The aim of this systematic review was to investigate the factors that influence the efficacy of community-based rehabilitation programmes in improving the quality of life and daily functioning of adults with severe traumatic brain injury.

Methods: A systematic review of the literature was conducted. In keeping with the principles of best evidence synthesis, the findings from the studies were analysed according to their methodological quality. Findings: Eleven studies were included in the review; synthesis of these studies revealed that the outcomes of community rehabilitation programmes are mediated by a complex interaction between programme characteristics, participant characteristics and the methods used to assess outcomes. Variations in study methodology and quality further impact the extent to which treatment effectiveness can be demonstrated. There was evidence to support the use of telephone counselling and interdisciplinary team rehabilitation. There was moderate strength evidence indicating the psychosocial benefits of engaging in group rehabilitation programmes.

Conclusions: Outcome measures designed specifically for use with traumatic brain injury clients in community settings need to be validated. The clinical and cost benefits of telephone counselling, peer support groups and interdisciplinary team rehabilitation programmes warrant further research.

Key words: $\square$ traumatic brain injury $\square$ rehabilitation $\square$ community-based $\square$ quality of life $\square$ functioning

Submitted 7 August; accepted for publication with minor revisions following double-blind peer review 5 September 2008

Lizzie Evans is a Rotational Band 5 Occupational Therapist, Neuropsychiatry, Whitchurch Hospital. Cardiff and Vale NHS Trust;

and Claire Brewis is Principal Lecturer and Subject Group Leader of Occupational Therapy at the University of Teesside,

Middlesbrough, UK

Author for

correspondence:

Email:lizzie.evans@ yahoo.co.uk
$\mathrm{M}$ edical advances have led to an increased survival rate for people with severe traumatic brain injury (TBI) (Ashley et al, 1997; Lefebvre et al, 2005). Surviving the initial trauma can mark the start of an uncertain future for the client and their caregivers, characterized by a complex web of physical and psychosocial impairments (Oddy and Herbert, 2003; Mateer et al, 2005; Verhaeghe et al, 2005; Duff, 2006). Psychosocial problems are considered to be the most disabling sequelae of TBI (Stilwell et al, 1999; Blundon and Smits, 2000; Trombly et al, 2002; Dikmen et al, 2003; Lefebvre et al, 2005; Eriksson et al, 2006). The full extent of these deficits often does not emerge until some time after hospital discharge, when difficulties in community reintegration become evident (Ponsford, 1995; Caetano and Christensen, 1999).

The long-term impact of a TBI is closely associated with the severity of injury sustained, with more severe injuries leading to greater deficits. A diagnosis of a severe brain injury results from one or more of the following criteria:
A Glasgow Coma Score of less than nine in the first 48 hours post-injury

An extended period of unconsciousness lasting over 24 hours

Evidence of post-traumatic amnesia lasting over 24 hours (Dawodu, 2008).

TBI represents a major public health and economic concern; and accounts for a significant proportion of young adults living with life-long disabilities (Ashley et al, 1997; Rice-Oxley and Turner Stokes, 1999; Dikmen, et al, 2003; Sarajuuri et al, 2005). The financial costs of meeting the long-term health and rehabilitative needs of TBI survivors (Cifu et al, 1999), coupled with the high unemployment rate among the TBI population (Vangel et al, 2005) has economic implications for society as a whole (Powell, 1999; Nair et al, 2006; Winkler et al, 2006).

The need to reduce the cost of acute health care has led to clients being discharged earlier from hospital (Cifu et al, 1999; Barnes and Radermacher, 2001). Shorter periods of inpatient rehabilitation are associated with poorer long-term outcomes (Benson Yody and Strauss, 1999) and greater burden on pri- 
mary caregivers (Paterson et al, 2001; Marks and Daggett, 2006). Interventions used in inpatient rehabilitation have been criticized for having limited relevance to client's social and physical environments (Powell, 1999). There is evidence that individuals with TBI and their caregivers continue to have high levels of unmet need following discharge from inpatient rehabilitative services (Kersel et al, 2001; Mellick et al, 2003; Eriksson et al, 2006). These factors combine to support the need for enhanced community services to help meet the long-term rehabilitation needs of adults with TBI (Wade, 2003).

There is debate in the literature regarding the definition of community-based rehabilitation (Wade, 2003; World Federation of Occupational Therapy, 2004). For the purpose of the current review it is defined as rehabilitation that takes place within the client's physical and social environment, for example in their home or other community facility (Powell, 1999; Wade, 2003; Sakellariou and Pollard, 2006). Hospital-based services are excluded from this definition. The aim of community rehabilitation is to enhance the client's quality of life and functional independence in the context of their regular roles and routines (Powell, 1999; Rice-Oxley and Turner Stokes, 1999) and to minimize the practical and psychological impact on the carers (Tyerman, 1999; Wood and Worthington, 1999).

The UK government has recently pledged to increase the accessibility and availability of community services (Department of Health, 2006) but community-based head injury teams have been slow to develop (Lefebvre et al, 2005). Having highlighted the need for extended community rehabilitation for adults with TBI; it becomes imperative to identify the factors influencing the effectiveness of such programmes. Resources can then be targeted to providing the most effective interventions.

A background literature review revealed a wealth of studies purporting to examine the efficacy of community rehabilitation programmes, however, the lack of a consistent definition of community rehabilitation is problematic. The current evidence for community rehabilitation covers a broad spectrum of services, the majority of which are based in outpatient or day-hospital units. The location and context of these programmes is not consistent with the concept of community rehabilitation being planned and delivered in the client's social and physical environment. The evidence-base informing the shift towards community-based services, as defined by the location of service delivery, is in its infancy (Rice-Oxley and Turner Stokes, 1999; Wade, 2003; Johnston et al, 2006). A rigorous, well-defined systematic review of the current literature is therefore warranted to guide service development, facilitate evidence-based practice and to indicate directions for future research.

\section{AIMS}

The aim of this systematic review was to investigate the factors which influence the efficacy of community-based rehabilitation programmes in improving the quality of life and functional capacity of adults with severe TBI. This was achieved by identifying the different types of interventions used in community settings, and by exploring their outcomes; taking into account differences in methodological design and quality.

\section{METHODS}

\section{Inclusion criteria}

\section{Studies}

This review considered randomized control trials, quasi-experimental studies, mixed methodologies and qualitative research that evaluated community rehabilitation programmes for adults affected by severe TBI. As there is no agreed gold standard study design in neurological rehabilitation research, different types of study design were included in the review. This reflects the diverse methodologies employed in neurological rehabilitation research and acknowledges the potential contribution of different types of research in informing evidence-based practice. To reduce reflexivity and enable standardized critical appraisal, only primary research papers were included. Opinion pieces and descriptive papers were excluded. Single case study designs were also excluded as small samples are susceptible to unstable effects (Slavin, 1995). Only articles published in English between 1996-2007 were considered.

\section{Participants}

Table 1 details the participant-specific inclusion criteria. Studies were also considered in which the participants were the carers of adults with TBI who met the criteria.

Table 1.

Participant-specific inclusion and exclusion criteria

\begin{tabular}{lll|l}
\hline $\begin{array}{l}\text { Participants } \\
\text { (Pps) }\end{array}$ & $\begin{array}{l}\text { Inclusion criteria } \\
\text { Diagnosis }\end{array}$ & $\begin{array}{l}\text { At least } 65 \% \text { of all Pps } \\
\text { have TBI }\end{array}$ & $\begin{array}{l}\text { Less than } 65 \% \text { of all Pps } \\
\text { have diagnosis of TBI }\end{array}$ \\
\hline Severity & $\begin{array}{l}\text { Over } 75 \% \text { of all Pps } \\
\text { have moderate or } \\
\text { severe injury }\end{array}$ & $\begin{array}{l}\text { Less than } 75 \% \text { of Pps } \\
\text { having moderate or severe } \\
\text { TBI; over } 10 \% \text { of Pps } \\
\text { have mild injury }\end{array}$ \\
\hline Age & $16-70$ years & $<16$ and $>70$ years \\
\hline Sample size & $n=>10$ & $n=<10$ \\
\hline
\end{tabular}




\section{Interventions}

The interventions of interest included any community rehabilitation programmes intended to improve the quality of life, functional independence and community participation of adults and their carers affected by TBI. Interventions delivered in hospi-tal settings, for example in day units and outpatient departments, were excluded from this review.

\section{Outcome measures}

Outcomes of interest were those that measured the quality of life, functional independence, physical, psychological and social functioning, and com-. munity participation of adults, and their caregivers affected by severe TBI.

\section{Search strategy and study selection}

Figure 1 details the process of study selection. One reviewer (LE) carried out the four-tiered search strategy, and screened all the study titles $(n=878)$ for relevance to the research topic. Two reviewers (LE and ZT) independently sifted the abstracts $(n=153)$ which led to 34 studies being identified for potential inclusion. Two reviewers independently reviewed the

eJournal indexes searched:

American Journal of Occupational Therapy, British Journal of Occupational

Therapy, Brain Injury and Journal of Head Trauma Rehabilitation.

Unpublished literature searches: Dissertation and thesis collections held at University of Teesside and College of Occupational Therapists, London

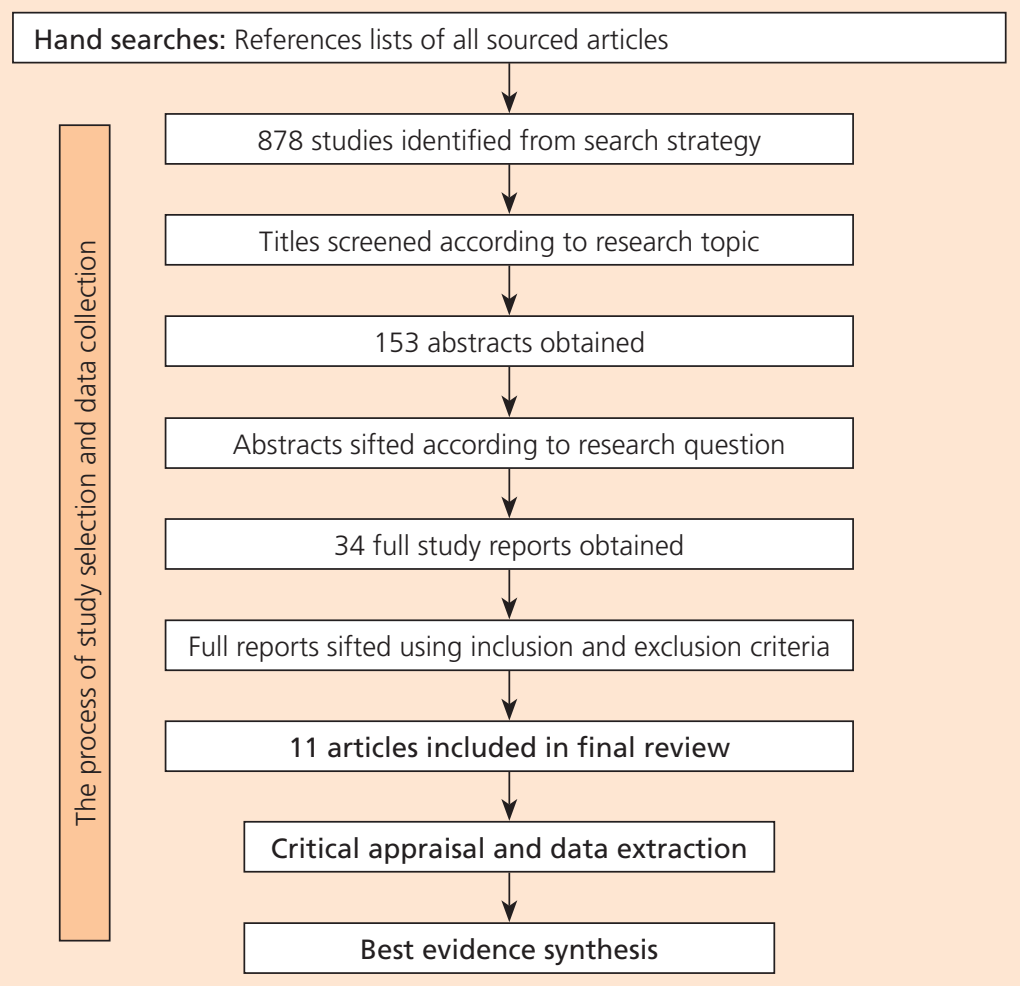

Figure 1. Diagram illustrating the search strategy and the process for study identification and selection full text of these studies and the inclusion and exclusion criteria were applied. A third party $(\mathrm{CB})$ was consulted for arbitration when consensus could not be reached following discussion between the reviewers regarding the inclusion of one paper. This process led to 11 articles being selected for final review, and these were appraised by the main author (LE).

\section{Critical appraisal}

The methodological quality of the studies was assessed using the Law et al (1998) McMaster Critical Review Tool for Qualitative and Quantitative Research. This tool is designed for appraising research evidence in relation to occupational therapy practice and enables comparison between different types of study design. Occupational therapy interventions aim to maximize functional independence and quality of life. This is consistent with the ethos of community rehabilitation programmes for adults with TBI, which often involves a range of professional disciplines. The McMaster tool was selected as it relates specifically to allied health research; it can be used to appraise both qualitative and quantitative research; it includes clear guidelines on the interpretation of each aspect of critical appraisal, and the appraisal process results in a non-numerical summary of overall study quality. All critical appraisal tools have limitations (Katrak, 2004); it was therefore decided to create an additional quality checklist based on the synthesis of four critical appraisal tools (Law et al, 1998; Batavia, 2001; Walsh and Wigens, 2003; Humphris, 2005), which addressed aspects of research quality not included in the McMaster tool. The overall quality of each study was determined using a combination of the detailed appraisal from the McMaster form, and the quality checklist. Studies were rated either as high quality, medium quality or low quality. Potential sources of bias affecting the study findings were weighted according to their likely impact on the overall study quality. Factors with highest weighting included sample size, length of follow-up period and use of appropriate control groups.

\section{Data collection}

A data extraction form was composed to elicit the information needed to address the review question. The form was piloted and amended to ensure that the necessary information was extracted. Authors were contacted by email when there was insufficient detail to complete the data extraction tables; this yielded a low response rate.

\section{Data synthesis}

Owing to the heterogeneous nature of the reviewed studies, statistical pooling (meta-analysis) of the results was not considered appropriate. Data synthesis therefore relied on descriptive techniques and 
critical appraisal to enable best evidence synthesis (Slavin, 1995).

The level of internal and external validity dictates the overall quality of a study. Internal validity relates to the extent to which error and bias are minimized, where high internal validity implies that the outcome of a study is owing to the effect of the treatment. External validity refers to the extent to which the findings can be generalized to the population of interest (Batavia, 2001). There are differing views regarding the relationship between internal and external validity. Khan et al (2001) consider internal validity to be a prerequisite for external validity, whereas Batavia (2001) argues that studies rarely have both high internal and external validity. He suggests that in the area of neurological rehabilitation, internal validity is often compromised in favour of external validity.

In this review the critical appraisal tool (Law et al, 1998) emphasized the importance of internal validity over external validity. Although the studies deemed to be low quality may have been susceptible to internal biases, the research methods employed may be more likely to reflect the reality of clinical practice, hence increasing their external validity. Best evidence synthesis credits equal value to internal and external validity (Slavin, 1995). Therefore in line with best evidence synthesis, it was decided that all reviewed studies would be included in the final report, while ensuring that the conclusions drawn reflect the strength of evidence as determined by the quality of the research.

\section{FINDINGS}

Eleven studies were included in the final review; two were assessed as being high quality (Bell et al, 2005; Powell et al, 2002a) five were medium quality (Thomas, 2004; Sinnakaruppan et al, 2005; Walker et al, 2005; Carnevale et al, 2006; Smith et al, 2006) and four were rated as being low quality (Bowen et al, 1999; Carnevale et al, 2002; Hibbard et al, 2002; Ponsford et al, 2006). Table 2 summarizes the key characteristics of the reviewed studies.

\section{Programme characteristics}

\section{Nature of the rehabilitation approaches used}

Six approaches to community rehabilitation were identified. Four studies evaluated the effect of interdisciplinary team rehabilitation programmes (Bowen et al, 1999; Powell et al, 2002a; Ponsford et al, 2006; Smith at al, 2006). Two studies investigated the effects of a home-based behavioural management programme (Carnevale et al, 2002; Carnevale et al, 2006). Two studies piloted outdoor experiential education programmes (Thomas, 2004;
Walker et al, 2005). Bell et al (2005) evaluated a telephone counselling service; Sinnakaruppan et al (2005) piloted an educational training programme involving clients and carers and Hibbard et al (2002) evaluated the impact of a communitybased peer support programme.

Bell et al (2005) carried out a high quality randomized controlled trial to establish the effectiveness of a telephone counselling service involving motivational interviewing, goal setting, problem solving and educational techniques. The intervention group demonstrated improvements in quality of life and functional status. No effect was detected in social or leisure participation, behavioural symptoms or occupational status.

Two studies (Carnevale et al, 2002; Carnevale et al, 2006) provide preliminary support for the use of natural setting behavioural management programmes (NSBM) in reducing problem behaviours, although neither study demonstrated an effect on caregiver stress or family functioning. Sinnakaruppan et al (2005) piloted group educational training programmes targeting memory, executive and emotional dysfunction. A positive relationship emerged between the intervention and quality of life, emotional and psychological well-being and independence in activities of daily living (Table 3).

Thomas (2004) and Walker et al (2005) evaluated a goal-orientated outward-bound programme. Participants in Thomas's (2004) study reported improved quality of life, greater self-awareness of functional deficits and improved coping strategies after completing the programme. Walker et al (2005) found no overall effect on participants' emotional and psychological wellbeing on standardized measures, but found participants achieved over $80 \%$ of their goals in social and leisure participation and occupational status.

The four studies which evaluated the effectiveness of interdisciplinary team community rehabilitation (Bowen et al, 1999; Powell et al, 2002a; Ponsford et al, 2006; Smith et al, 2006) involved collaborative goal setting between the client, carers and therapists. Powell et al (2002) found that interdisciplinary team rehabilitation led to improved functional independence. None of the interdisciplinary team community rehabilitation programmes showed an effect on anxiety, depression, social functioning or employment status. Variation between the studies in team composition, participant characteristics and methodological quality, coupled with lack of detail regarding treatment duration and intensity mean there is insufficient evidence to identity the most influential factors in determining the effectiveness of community interdisciplinary team rehabilitation programmes.

Hibbard et al (2002) used a Participation Action 


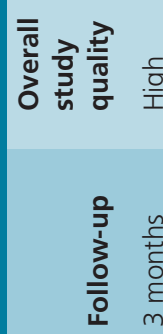

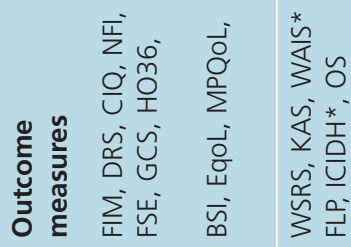

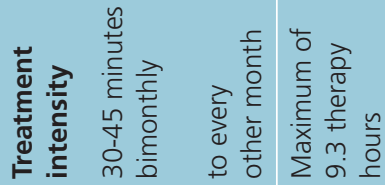

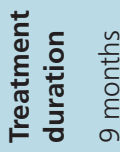

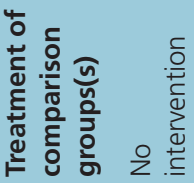

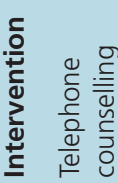

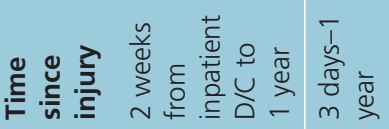

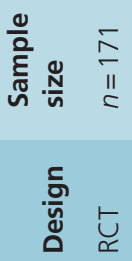

릉 पㅇำ

กั

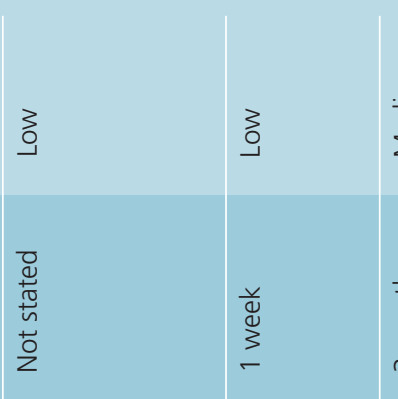

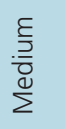

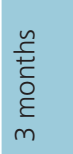

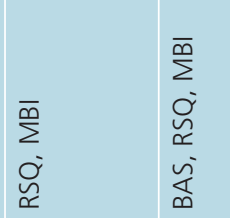

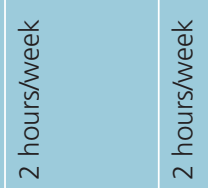

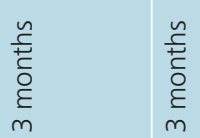

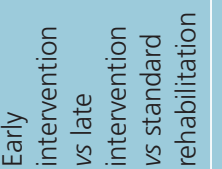

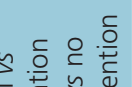

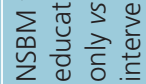

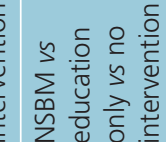

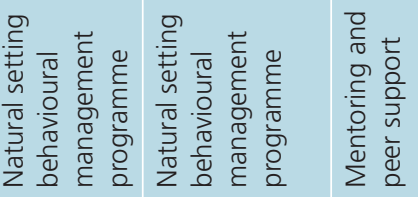

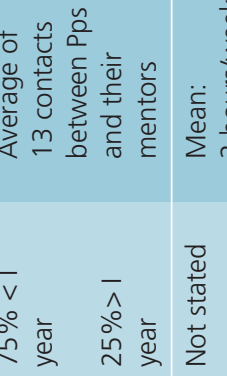

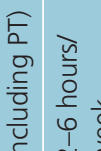

\begin{tabular}{|c|c|c|}
\hline 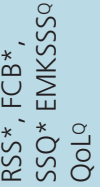 & 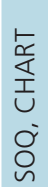 & 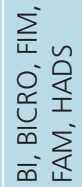 \\
\hline
\end{tabular}

華華

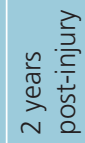

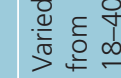

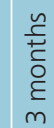

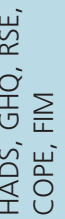

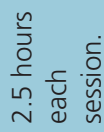

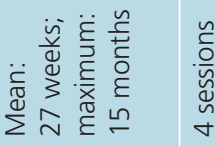

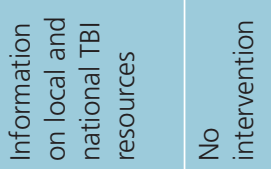

总

亲它方

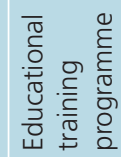

흥

总它念

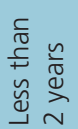

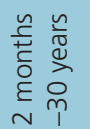

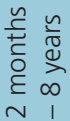

\section{다일}

$\frac{\varepsilon}{\frac{\varepsilon}{\partial}}$

\section{.}



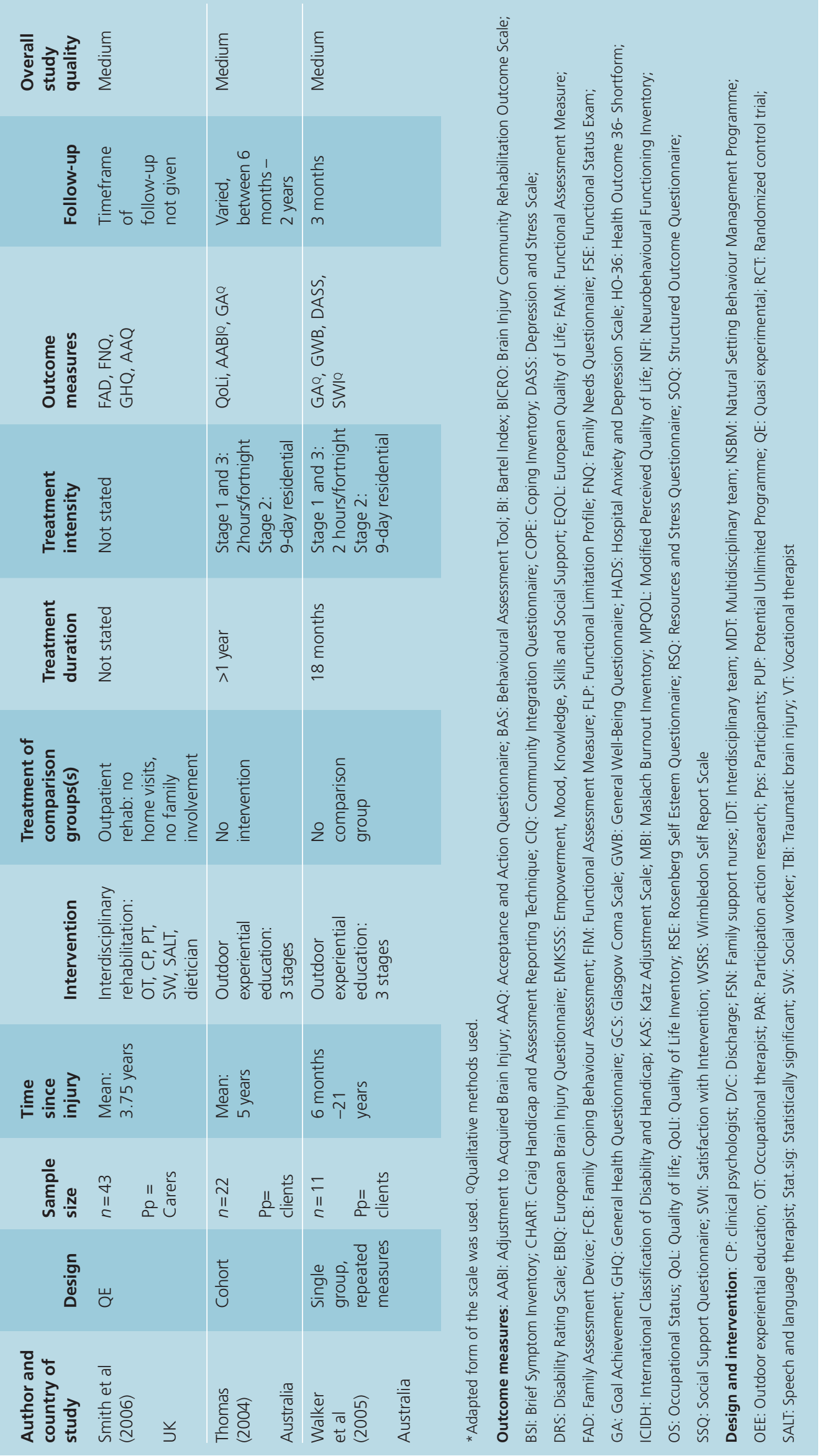
Table 3.

A summary of the outcomes of different types of community rehabilitation for clients with traumatic brain injury and their care

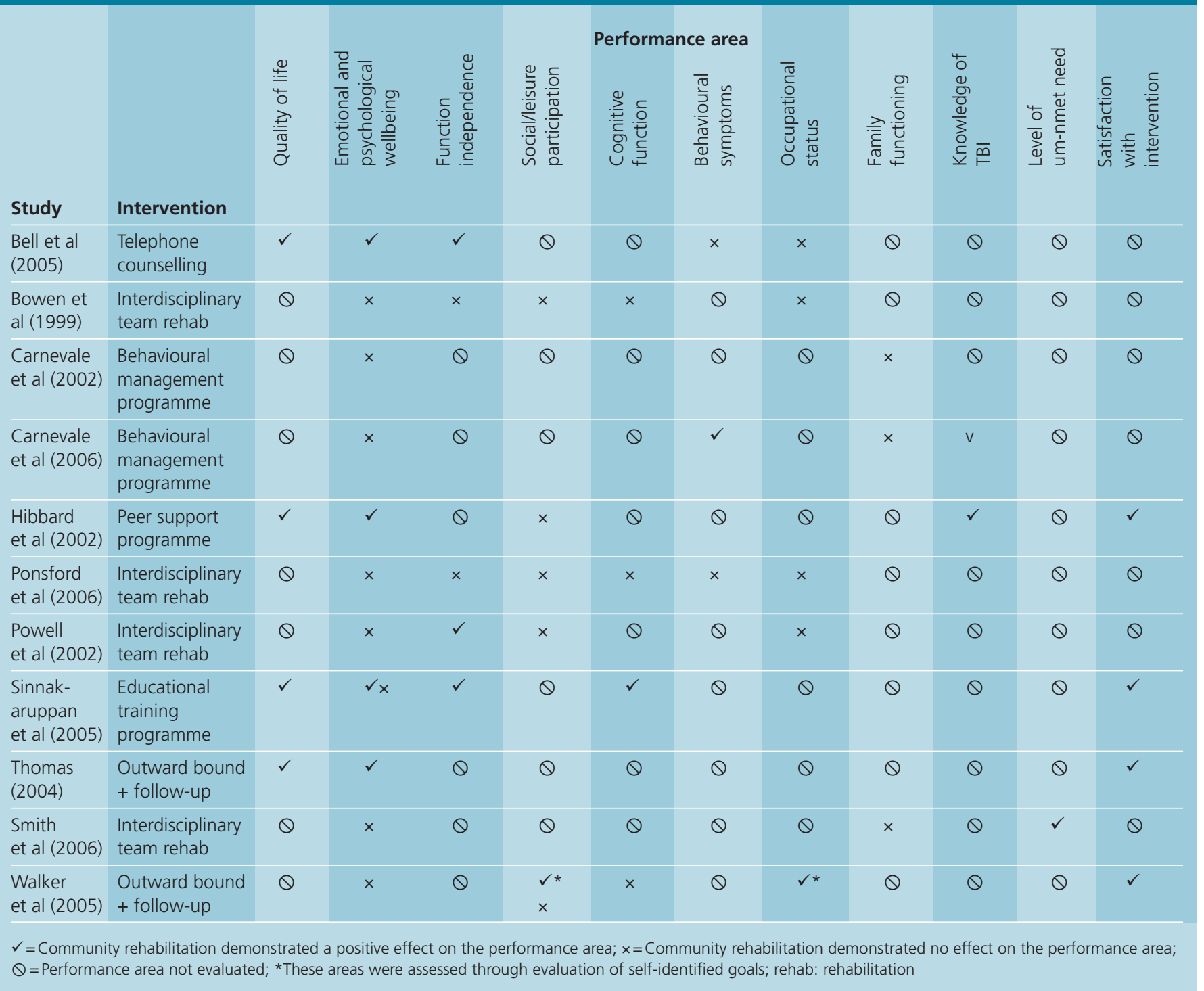

Research (PAR) approach to evaluate the efficacy of a mentor-peer support partnership programme. Although rated as low quality on quantitative criterion, this study provides qualitative support for the potential benefit of peer-mentor programmes in improving the quality of life, emotional and psychological wellbeing, and knowledge of TBI of clients and carers.

Carer involvement in the rehabilitation process Eight of the eleven reviewed studies (Bowen et al, 1999, Carnevale et al 2002, Hibbard et al, 2002; Powell et al, 2002a; Sinnakaruppan et al, 2005; Carnevale et al, 2006; Ponsford et al, 2006; Smith et al, 2006) involved carers in the intervention and/ or evaluation stages of the community rehabilitation programmes. None of the three studies assessing the impact of community rehabilitation on family functioning demonstrated an effect (Carnevale et al, 2002; Carnevale et al, 2006; Smith et al, 2006). This is likely to be associated with the lack of family involvement in the rehabilitation process. Family systems theory posits that in order for family functioning to improve, the entire family unit must be involved in the intervention process, not just the main carer and client (Gill and Wells, 2000; Kreutzer et al, 2002; Verhaeghe et al, 2005; Duff, 2006; Gan et al, 2006).

\section{Comparison of individual and group rehabilitation programmes}

Seven studies evaluated community rehabilitation involving individualized therapy programmes (Bowen et al, 1999; Carnevale et al, 2002; Powell et al, 2002a; Bell et al, 2005; Carnevale et al, 2006; Ponsford et al, 2006; Smith et al, 2006). Four studies evaluated community rehabilitation programmes involving group work or partnerships (Hibbard et al, 2002; Thomas, 2004; Sinnakaruppan et al, 2005; Walker et al, 2005). Overall, the programmes involving group work demonstrated greater treatment 
effects than those involving individual therapy programmes. There is also qualitative evidence that peer support from group programmes improves psychosocial functioning (Hibbard et al, 2002; Thomas, 2004).

Other research which failed to meet the inclusion criteria by a narrow margin could lend support to the benefits of peer-support groups for TBI clients in facilitating improvements in quality of life and psychosocial functioning (Armengol, 1999; Vandiver and Christofero-Snider, 2000; Bedard et al, 2003; Forman et al, 2006).

\section{Treatment intensity and duration}

The intensity and duration of the community rehabilitation programmes varied considerably. Owing to the variation in details provided, it was not possible to establish the number of therapy hours per month for each study. It is therefore difficult to draw conclusions on the effect of treatment intensity on rehabilitation outcomes. Increased treatment intensity has been associated with improved outcomes in inpatient rehabilitation following TBI settings (Shiel et al, 2001; Cifu et al, 2003). The relationship between treatment outcomes and the length and intensity of community rehabilitation is less clear, and needs further investigation.

\section{Participants characteristics}

A variety of client variables have been shown to influence outcomes following TBI rehabilitation. These include demographic factors, injury variables, pre-injury risk factors and social factors (Johnston and Miklos, 2002; Powell et al, 2002b). The inclusion criteria were aimed at reducing the effect of these confounding variables but owing to the heterogeneous nature of the client group, it is not possible to account for all sources of variation. Participants varied in the length of time between sustaining their injuries and beginning community rehabilitation. Combining the results for those who were less than a year post-injury, and those over 2 years post-injury may skew the findings, as spontaneous recovery may advantage the outcomes of those with recent injuries.

The link between rehabilitation outcomes and the period of time since sustaining the injury was considered. Four studies (Powell et al, 2002a; Thomas, 2004; Sinnakaruppan et al, 2005; Walker et al, 2005) demonstrated that participants who were several years post-injury made notable improvements in function and quality of life. This contests the notion that the window of recovery following TBI is limited to the first 2 years (Coetzer and Rushe, 2005). Rehabilitation outcomes may be more influenced by the client's level of motivation, compliance to rehabilitation and self-awareness of deficits (Sabin, 2005).

\section{Outcomes areas and outcome methods}

Evidence for the efficacy of community rehabilitation programmes may be influenced by the choice of outcome areas and assessment tools used. Outcome measures should reflect the multidimensional nature of the rehabilitation process (Ponsford et al, 1999) and should capture clinically significant changes in function, rather than solely statistically significant changes (Cicerone, 2004).

A variety $(n=41)$ of standardized assessment tools, self-report measures and qualitative techniques were used to evaluate the efficacy of the community rehabilitation programmes. The 41 outcome measures were listed and then categorized into broader groups according to the areas of function or deficit they assessed. This resulted in 11 broad outcome areas being identified, which are listed in Table 3.

Several limitations associated with the methods of outcome assessment warrant attention. First of all, several studies used outcome measures designed for use in inpatient settings to capture the community functioning of adults with TBI. Measures used out of context are more liable to ceiling effects and therefore may not give an accurate representation of function (Powell et al, 2005) Secondly, evidence has shown that standardized measures often do not accurately reflect a client's level of day-to-day functional independence (Sbordone, 2001; Wilson, 2003). In light of this, the results for the five studies (Bowen et al, 1999; Powell et al, 2002a; Bell et al 2005; Ponsford et al, 2006; Sinnakaruppan et al 2006) which used standardized measures to assess functional independence may need to be treated cautiously. Thirdly, outcomes assessed by self-report tools may be liable to the effects of subjectivity, response shift and social desirability bias (Bowling, 2002; Johnston and Miklos, 2002; Johnston et al, 2006). This potentially threatens the reliability of findings for all reviewed studies as the majority of outcomes were assessed using self-report tools.

Qualitative approaches and individualized goal setting are alternative means of assessing outcomes which may have greater relevance to client's daily function. The use of self-identified goals may not stand up to rigorous statistical scrutiny, but the clinical significance of clients meeting their rehabilitation goals should be recognized. Individualized goal setting is congruent with the philosophy of clientcentred rehabilitation, but caution must be exercised when working with clients who have impaired selfawareness (Malec, 1999; Russell and Powell, 1999; Liu et al, 2004) as they may set unrealistic rehabilitation goals. The frustration associated with unattainable goal setting could have a detrimental effect on clients' adherence to treatment programmes (Levack et al, 2006). Similarly, if the goals do not provide a challenge, they will be of little therapeutic benefit. 
Improved quality of life has been identified as the ultimate goal of community rehabilitation (Johnston and Miklos, 2002). Attempts to define and conceptualize this complex construct has led to a range of definitions. Some emphasize the relationship between expected levels of function and actual levels of function and others focus more on overall measures of wellbeing and satisfaction. The lack of a consistent definition and the variety of assessment tools may result in quality of life being sidestepped in clinical practice and research outcomes (Bowling, 2002; Corrigan et al, 2001; Mailhan, 2005; SteadmanPare et al, 2001). The inclusion of quality of life as a stand-alone rehabilitation outcome corresponds to a client-centred rehabilitative model of practice. This also reflects the fact that quality of life cannot be predicted solely on the basis of improvements in physical or psychosocial functioning (Wood and Worthington, 1999; Corrigan et al, 2001; SteadmanPare, 2001; Cicerone, 2004; Mailhan, 2005).

The Post Acute Rehabilitation Measure (Powell et al, 2005) was designed to measure the extent of disability and participation restriction of adults with TBI living in the community. It comprises a 56-item questionnaire, completed by the carers of adults with TBI across five functional domains; self-care, emotion, cognition, movement and communication. Initial trials have shown promising validity and reliability (Powell et al, 2005). If further trials confirm the usefulness of this measure, it may be a valuable tool for community rehabilitation teams working with adults with TBI; overcoming some of the limitations of other standardized assessments.

When considering the overall treatment effects of the reviewed studies (Table 3), it can be seen that the majority of functional outcome areas were largely resistant to change. The two outcome areas which demonstrated greatest treatment effect were quality of life and functional independence. Of the seven studies (Bowen et al, 1999; Hibbard et al, 2002; Powell et al, 2002a; Thomas, 2004; Bell et al, 2005 Sinnakaruppan et al 2005; Ponsford et al, 2006) which assessed the effect of community rehabilitation on quality of life and functional independence, the only two which failed to show a treatment effect were methodologically weak (Bowen et al, 1999; Ponsford et al, 2006). When excluding the low quality studies, it can be seen that there is preliminary evidence for the efficacy of telephone counselling, interdisciplinary team rehabilitation, educational group training and a group outward bound course in improving the quality of life and functional independence of adults with TBI.

\section{Methodological quality of the studies}

Studies with small sample sizes lack statistical power and are subject to unstable effects, which reduces the extent to which findings can be generalized (Johnston et al, 2006). The findings of six of the reviewed studies may be limited, owing to small sample sizes $(n=<50)$ (Carnevale et al, 2002; Hibbard et al, 2002; Thomas, 2004; Walker et al, 2005; Carnevale et al, 2006; Smith et al, 2006).

The length of the follow-up period is important when considering the stability of the treatment effect. This is particularly relevant in TBI rehabilitation where interventions are aimed at achieving longterm changes. The conclusions from three studies (Bowen et al, 1999; Carnevale et al, 2002; Hibbard et al 2002) should be treated cautiously owing to the lack of a follow-up assessment at a minimum of 3 months after treatment. Control groups are used to reduce the effect of confounding variables influencing the outcomes. Three studies (Hibbard et al, 2002; Walker et al, 2005; Ponsford et al, 2006) lacked an appropriate control group which reduces the reliability of findings.

Methods of data analysis can influence research outcomes. In quantitative research, the clinical significance of study results is often inferred through statistical significance (Hicks, 2004). This approach has been criticized for over-simplifying a complex interaction. Powell et al (2002a) acknowledged the distinction between clinical and statistical significance by calculating a 'maximal gain score'. This enables interpretation of the potential clinical impact of their results. This direct application of research findings to a client's daily function increases the external validity and clinical relevance of the study. Caution must also be exercised in interpreting the results of Sinnakaruppan et al's (2005) study, owing to the large number of statistical tests conducted. This increases the risk that positive associations between variables may have arisen by chance (Bowling, 2005) rather than being directly attributable to the efficacy of the intervention.

\section{CONCLUSIONS}

\section{Summary of the reviewed evidence}

This systematic review sought to investigate the factors that influence the efficacy of community rehabilitation programmes for adults with TBI. Synthesis of the eleven reviewed studies revealed that the outcomes of these programmes are mediated by a complex interaction between programme characteristics, participant characteristics and the methods used to assess outcomes. Variations in study methodology and quality impact the extent to which treatment efficacy can be demonstrated.

There is evidence to suggest that a telephone counselling service may lead to sustained improvements in quality of life, psychosocial functioning and independence in activities of daily living 
(Bell et al, 2005). There is preliminary support for NSBM programmes in reducing problem behaviours (Carnevale et al 2006). Sinnakaruppan et al (2005) present encouraging findings for an educational group-training programme that simultaneously meets the informational and psychosocial needs of clients and carers. A high quality randomized controlled trial indicates that interdisciplinary team community rehabilitation can lead to gains in functional independence, but it failed to show a treatment effect in other functional areas (Powell et al, 2002a). There is qualitative evidence for the psychosocial benefits in engaging in a group outward-bound programme (Thomas, 2004) and a mentoring partnership programme (Hibbard et al, 2002).

\section{Limitations of the review}

Only one reviewer was involved in the data extraction and critical appraisal process. Although the use of a critical appraisal tool increases the rigour and consistency of the quality evaluation, this process is subjective and therefore may be susceptible to researcher bias. Several measures were implemented to minimize researcher bias; the use of inclusion and exclusion criteria, the rigorous search strategy and the use of a standardized critical appraisal tool.

\section{Implications for practice}

Community brain injury teams often cover a large geographical area, limiting the time available to carry out regular face-to-face interventions with clients. This review lends support to the potential benefit of supplementing traditional rehabilitation techniques with telephone counselling. This may reduce the number of face-to-face sessions needed, which has positive implications for the client and the service provider. For clients who need long-term support from rehabilitation teams, telephone-based therapy may be a cost-effective way of meeting their needs and enabling on-going goal setting. Peer-support groups may be a cost effective way of facilitating psychosocial adjustment for clients and carers after TBI. They may also help to bridge the gap when clients are discharged from formalized rehabilitation services, which can be a challenging time for clients and carers.

Evidence suggests that clients can benefit from community rehabilitation many years after TBI. Policy makers should therefore consider how clients could access these services at different stages of the recovery process, taking into account the importance of client motivation in determining rehabilitation outcomes (Ashley et al, 1997; Tyerman, 1999).

\section{Directions for further research}

The evidence base for the efficacy of community rehabilitation for adults with TBI is in its infancy. As community rehabilitation is being given increasing clinical and political attention, the need to conduct rigorous larger-scale research projects becomes imperative (Johnston et al, 2006). The development of valid and reliable outcome measures to assess outcomes of community rehabilitation needs to be prioritized (Johnston and Miklos, 2002; Ragnarsson, 2006). This review indicates that the interventions warranting further investigation are telephone counselling and programmes involving mentoring and peer support. Internet-based support groups, which combine the flexibility of remote interventions such as telephone counselling with the benefits of peer support, may also be worth investigating. Interdisciplinary team community rehabilitation also needs further investigation to establish the most effective formula in terms of programme composition and intensity. In addition to investigating clinical effectiveness, the cost-effectiveness of community rehabilitation programmes should be established (Caetano and Christensen, 1999). To develop the evidence base on the efficacy of community rehabilitation programmes, therapists are urged to ensure that relevant, reliable outcome measures are used to quantifiably demonstrate the therapeutic benefits of the services they provide. IJTR

Conflict of interest: none

The authors would like to acknowledge the contribution of Zoë Tennyson and thank for her time and assistance in the initial stages of the review process.

Ashley MJ, Persel CS, Clark MC, Krych DK (1997) Longterm follow up of post-acute traumatic brain injury rehabilitation: A statistical analysis to test for stability and predictability of outcome. Brain Inj 11(7): 677-90

Armengol CG (1999) A multimodal support group with hispanic traumatic brain injury survivors. J Head Trauma Rehabil 14(3): 233-46

Barnes MP, Radermacher H (2001) Neurological rehabilitation in the community. J Rehabil Med 33: 1244-8

Batavia M (2001) Clinical Research for Health Professionals: A User Friendly Guide. Butterworth Heinemann, Oxford

Bedard M, Felteau M, Mazmanian D et al (2003) Pilot evaluation of a mindfulness-based intervention to improve the quality of life among individuals who sustained traumatic brain injuries. Disabil Rehabil 25(13): 722-31

Bell KR, Tempkin NT, Esselman PC et al (2005) The effect of a scheduled telephone interview on outcome after moderate to severe traumatic brain injury: A randomised control trial. Arch Phys Med Rehabil 86: 851-2

Benson Yody B, Strauss D (1999) The effect of decreasing lengths of stay on long term TBI patient outcomes. Journal of Rehabilitation Outcomes Measurement 3(3): 42-50

Blundon G, Smits E (2000) Cognitive rehabilitation: A pilot survey of therapeutic modalities used by Canadian occupational therapists with survivors of traumatic brain injury. Can J Occup Ther 67(3): 184-96

Bowen A, Tennant A, Neumann V, Chamberlain A (1999) Evaluation of a community-based neuropsychological service for people with traumatic brain injury. NeuroRehabilitation 13: 147-55

Bowling A (2002) Research Methods in Health: Investigating Health and Health Services, 2nd edn. Open University Press, Buckingham:

Caetano C, Christensen AL (1999) Outpatient/day rehabilitation at the centre for rehabilitation of brain injury, Copenhagen, Denmark. Neuropsychol Rehabil 9(3/4): 447-56

Carnevale CJ, Anselmi V, Busichio K, Millis SR (2002) Changes in ratings of caregiver burden following a community-based behaviour management programme for persons with traumatic brain injury. J Head Trauma Rehabil 17(2): 83-95 
Carnevale CJ, Anselmi V, Johnston M, Busichio K, Walsh V (2006) A Natural Setting Behaviour Management Programme For Persons With Acquired Brain Injury: A Randomised Control Trial. Arch Phys Med Rehabil 87: 1289-97

Cicerone KD (2004) Participation as an outcome of Traumatic Brain Injury Rehabilitation. J Head Trauma Rehabil 19(6): 494-501

Cifu DX, Kreutzer JS, Marwitz JH et al (1999) Etiology and incidence of rehospitalization after traumatic brain injury: A multicentre analysis. Arch Phys Med Rehabil 80: 85-90

Cifu DX, Kreutzer JS, Kolakowsky-Hayner SA, Marwitz JH, Englander J (2003) The relationship between therapy intensity and rehabilitative outcomes after traumatic brain injury: A multicenter analysis. Arch Phys Med Rehabil 84: 1441-8

Coetzer R, Rushe R (2005) Post-acute rehabilitation following traumatic brain injury: Are both early and later improved outcomes possible? Int J Rehabil Res 28: 361-3

Corrigan JD, Bogner JA, Mysiw WJ, Clinchot D,Fugate L (2001) Life satisfaction after traumatic brain injury. J Head Trauma Rehabil 16(6): 543-55

Dawodu ST (2008) Traumatic brain injury: Definition, epidemiology, pathophysiology. Emedicine, WebMD. http://www. emedicine.com/PMR/topic212.htm. (accessed 22 September 2008)

Department of Heath (2006) Our Health, Our Care, Our Say: a New Direction for Community services. DH, London

Dikmen SS, Machamer JE, Powell JM, Tempkin NR (2003) Outcome 3 to 5 years after moderate to severe traumatic brain injury. Arch Phys Med Rehabil 84: 1449-57

Duff D (2006) Family impact and influence following severe traumatic brain injury. Axon 27(2): 9-23

Eriksson G, Tham K, Borg J (2006) Occupational gaps in everyday life 1-4 years after acquired brain injury. $J$ Rehabil Med 38: $159-65$

Forman ACM, Vesey PA, Lincoln NB (2006) Effectiveness of an adjustment group for brain injury patients: A pilot evaluation. International Journal of Therapy and Rehabilitation 13(5): $223-8$

Gan C, Campbell KA, Gemeinhardt M, McFadden G (2006) Predictors of family system functioning after brain injury. Brain Inj 20(6): 587-600

Gill DJ, Wells DL (2000) Forever different: Experiences of living with a sibling who has a traumatic brain injury. Rehabil Nurs 25(2): 48-53

Hibbard MR, Cantor J, Charatz H et al (2002) Peer support in the community: Initial findings of a mentoring program for individuals with traumatic brain injury and their families. $J$ Head Trauma Rehabil 17(2): 112-31

Hicks C (2004) Research Methods for Clinical Therapists: Applied Project design and Analysis, 4th edn. Churchill Livingstone, Edinburgh

Humphris D (2005) Types of Evidence. In: Hamer S, Collinson G. eds. Achieving Evidence Based Practice: A handbook for Practitioners. Balliere Tindall, Edinburgh

Johnston MV, Miklos CS (2002) Activity related quality of life in rehabilitation and traumatic brain injury. Arch Phys Med Rehabil 83(Supp1 2): S26-38

Johnston M, Sherer M, Whyte J (2006) Applying evidence standards to rehabilitation research. Am J Phys Med Rehabil 85(4): 292-309

Katrak P, Bialocerkowski A, Massy-Westropp N, Kumar S, Grimmer K (2004) A systematic review of the content of critical appraisal tools. BMC Med Res Methodol 4: 22

Kersel DA, Marsh NV, Havill JH, Sleigh JW (2001) Psychosocial functioning during the year following severe traumatic brain injury. Brain Inj 15(8): 683-96

Khan K, Kleijnen J (2001) Stage II Conducting the Review, phase 4: Selection of Studies. In: Khan K, Riet G, Glanville J, Sowden AJ, Kleijnen J, eds. Undertaking Systematic Reviews of Research on Effectiveness: CRD's Guidance for those Carrying out or Commissioning Reviews. York Publishing Services, York

Kreutzer JS, Hayner SA, Demm S, Meade M (2002) A structured approach to family intervention after brain injury. $J$ Head Trauma Rehabil 17(4): 349-67

Law M, Stewart D, Pollock N, Letts L, Bosche J, Westmorland M (1998) Critical Review Form - Quantitative Studies. McMaster University. http://www.fhs.mcmaster.ca/rehab/ ebp/pdf/quanreview.pdf (accessed 22 September 2008)

Lefebvre H, Pelchat D, Swaine B, Gelinas I, Levert MJ (2005) The experiences of individuals with traumatic brain injury, families, physicians, health professionals regarding care provided throughout the continuum. Brain Inj 19(8): 585-97

Levack WM, Taylor K, Slegart RJ, Dean SG, McPherson K,
Weatherall M (2006) Is goal planning in rehabilitation effective? A systematic review. Clin Rehabil 20: 739-55

Liu C, McNeil J, Greenwood R (2004) Rehabilitation outcomes after brain injury: Disability measures or goal achievement? Clin Rehabil 18: 398-404

Mailhan L, Azouvi P, Dazord A (2005) Life satisfaction after severe traumatic brain injury. Brain Inj 19(4): 227-38

Malec JF (1999) Goal attainment scaling in rehabilitation. Neuropsychol Rehabil 9(3/4): 253-75

Marks JP, Daggett LM (2006) A critical pathway for meeting the needs of families with severe traumatic brain injury. $J$ Neurosci Nurs 38(2): 84-9

Mateer CA, Sira CS, O'Coonnell ME (2005) Putting humpty dumpty together again: The importance of integrating cognitive and emotional interventions. $J$ Head Trauma Rehabil 20(1): $62-75$

Mellick D, Gerhart KA, Whiteneck GC (2003) Understanding outcomes based on the post-acute hospitalisation pathways followed by persons with traumatic brain injury. Brain Inj 17(1): 55-71

Nair A, Turner Stokes L, Tyerman A (2006) Vocational rehabilitation for acquired brain injury in adults (Protocol). Cochrane Database Syst Rev 2: CD006021

Oddy M, Herbert C (2003) Intervention with families following brain injury: Evidence-based practice. Neuropsychol Rehabil 13: 259-73

Paterson B, Kieloch B, Gmiterek J (2001) 'They Never Told Us Anything': Post discharge instruction for families of persons with brain injuries. Rehabil Nurs 26(2): 48-53

Ponsford J (1995) Returning to the Community after TBI. In Ponsford J, Sloan S, Snow P, eds. Traumatic Brain Injury: Rehabilitation for Everyday Living. Psychology Press, Hove

Ponsford J, Olver J, Nelms R, Curran C, Ponsford M (1999) Outcome measurement in an inpatient and outpatient traumatic brain injury rehabilitation programme. Neuropsychol Rehabil 9(3/4): 517-34

Ponsford J, Harrington H, Olver J, Roper M (2006) Evaluation of a community-based model of rehabilitation following traumatic brain injury. Neuropsychol Rehabil 16(3): 315-28

Powell J (1999) Assessment of rehabilitation outcomes in community/outreach settings. Neuropsychol Rehabil 9(3/4): 457-72

Powell J, Heslin J, Greenwood R (2002a) Community-based rehabilitation after severe traumatic brain injury: A randomised control trial. J Neurol Neurosurg Psychiatry $\mathbf{7 2}$ 192-202

Powell JM, Temkin NR, Machamer JE, Dikmen SS (2002b) Nonrandomized studies of rehabilitation for traumatic brain injury: Can they determine effectiveness? Arch Phys Med Rehabil 83: $1235-44$

Powell T, Wright L, Plumb J, Atkins R, Pantke R, Kalmus E (2005) Validation of a new measure for post acute rehabilitation. International Journal of Therapy and Rehabilitation 12(2): $63-70$

Ragnarsson KT (2006) Research-generated knowledge related to spinal cord injury, traumatic brain injury and burn injury. Am J Phys Med Rehabil 85(4): 289-91

Rice-Oxley M, Turner Stokes L (1999) Effectiveness of brain injury rehabilitation. Clin Rehabil 13(suppl 1): 7-24

Russell ML, Powell LJ (1999) Measurement in a peripatetic community-based head injury rehabilitation service. Neuropsychol Rehabil 9(3/4): 473-80

Sabin KL (2005) Older adults and motivation for therapy and exercise: Issues, influences, and interventions. Topics in Geriatric Rehabilitation 21(3): 215-20

Sakellariou D, Pollard N (2006) Rehabilitation: In the community or with the community? The British Journal of Occupational Therapy 69(12): 562-6

Sarajuuri JM, Kaipio ML, Koskinen SK, Niemela MR, Servo AR, Vilkki JS (2005) Outcome of a comprehensive neurorehabilitation program for patients with traumatic brain injury. Arch Phys Med Rehabil 86: 2296-302

Sbordone RJ (2001) Limitations of neuropsychological testing to predict the cognitive and behavioural functioning of persons with brain injury in real-world settings. NeuroRehabilitation 16: 199-201

Shiel A, Burn J, Clark D, Wilson B, Burnett M, McLellan DL (2001) The effects of increased rehabilitation therapy after brain injury: Results of a prospective controlled trial. Clin Rehabil 15: 501-14

Sinnakaruppan I, Downey B, Morrison S (2005) Head injury and family carers: A pilot study to investigate an innovative community-based educational programme for family carers and patients. Brain Inj 19(4): 283-308

Slavin RE (1995) Best evidence synthesis: An intelligent alter- 
native to meta-analysis. $J$ Clin Epidemiol 48(1): 9-18

Smith M, Vaughn FL, Cox LJ, McConville H, Roberts M, Stoddart S, Lew AR (2006) The impact of community rehabilitation for acquired brain injury on carer burden. J Head Trauma Rehabil 21(1): 76-81

Steadman-Pare D, Colantonio A, Ratcliffe G, Chase S, Vernich L (2001) Factors associated with perceived quality of life many years after traumatic brain injury. J Head Trauma Rehabil 16(4): 330-42

Stilwell P, Stilwell J, Hawley C, Davies C (1999) The national traumatic brain injury study: Assessing outcomes across settings. Neuropsychol Rehabil 9(3/4): 277-93

Thomas M (2004) The potential unlimited programme: An outdoor experiential education and group work approach that facilitates adjustment to brain injury. Brain Inj 18(12): 1271-86

Trombly CA, Radomski MV, Trexel C, Burnett-Smith SE (2002) Occupational therapy and achievement of self identified goals by adults with acquired brain injury: Phase II. Am J Occup Ther 56: 489-98

Tyerman A (1999) Outcome measurement in a community head injury service. Neuropsychol Rehabil 9(3/4): 481-91

Vandiver V, Christofero-Snider C (2000) TBI Club: A psychosocial support group for adults with traumatic brain injury. Journal of Cognitive Rehabilitation 18(4): 22-7

Vangel SJ, Rapport LJ, Hanks RA, Black KL (2005) Long-term medical care utilization and costs among traumatic brain injury survivors. Am J Phys Med Rehabil 84(3): 153-60

Verhaeghe S, Defloor T, Grypdonck M (2005) Stress and coping among families of patients with traumatic brain injury: A review of the literature. J Clin Nurs 14: 1004-12

Wade DT (2003) Community rehabilitation, or rehabilitation in the community. Disabil Rehabil 25(15): 875-81

Walker AJ, Onus M, Doyle M, Clare J, McCarthy K (2005) Cognitive rehabilitation after severe traumatic brain injury: A pilot programme of goal planning and outdoor adventure course participation. Brain Inj 19(14): 1237-41

Walsh M, Wigens L (2003) Introduction to Research. Nelson Thornes, Cheltenham

Wilson BA (2003) Goal planning rather than neuropsychological tests should be used to structure and evaluate cognitive rehabilitation. Brain Impair 4(1): 25-30

Winkler D, Unsworth C, Sloan S (2006) Factors that lead to successful community integration following severe trau- matic brain injury. J Head Trauma Rehabil 21(1): 8-21

Wood RL, Worthington AD (1999) Outcome in community rehabilitation: Measuring the social impact of disability. Neuropsychol Rehabil 9(3/4): 505-16

World Federation of Occupational Therapists (2004) WFOT position paper on community-based rehabilitation. www. wfot.org/documents.asp (accessed 22 September 2008)

\section{KEY POINTS}

- Individuals with traumatic brain injury (TBI) and their caregivers have high levels of unmet need following discharge from inpatient services. As health-care policies focus more on community-based services, there is a need to explore the efficacy of these services and how they may be enhanced for clients with TBI.

- A systematic review was undertaken to investigate the factors which influence the efficacy of community-based rehabilitation programmes in improving the quality of life and functional capacity of adults with severe TBI.

- Findings suggest that the outcomes of community rehabilitation programmes are mediated by a complex interaction between programme characteristics, participant characteristics, and the methods used to assess outcomes.

There is evidence to support the use of distance technologies, such as telephone counselling, in working with adults with TBI and their carers. Group work is also associated with greater improvements in functional status.

- Future research must ensure the validation of appropriate outcome measures designed specially for use in this population and interventions involving alternative methods of distance technologies and use of peer support groups should be explored.

\section{COMMENTARY}

Traumatic brain injury (TBI) commonly affects people who are in the prime of life and results in a high degree of variability in recovery outcomes (Reisetter and Abreu, 2005). Following acute and inpatient rehabilitation, the need for communitybased rehabilitation to enhance re-engagement in socially valued occupations is recognized (Powell et al, 2002). The authors of this systematic review of eleven studies conclude that there is some evidence that a range of community rehabilitation programmes can be effective even after many years. Included in these findings are programmes that focus on a broad range of interventions from telephone counselling to peer group support. So while the review is use- ful as a base line for rehabilitation and therapy professionals, there is further work needed to provide an evidence base for future practice.

Conducting a systematic review is no small feat and the authors are commended for their attempts to draw together such a diverse range of studies. This critical review provides clear justification of the process adopted and clearly identifies the limitations of the review and its tentative implications for practice and future research.

Several authors have previously conducted reviews of rehabilitation outcomes for people with brain injury. Together with the current review, these authors demonstrate that the range of interventions included under the rehabilitation banner are multidisciplinary and include various approaches that aim to address different outcomes. There is a lack of uniformity of outcome measures, agreed definitions and standardized interventions making it problematic to compare the results (Carney et al, 1999; Chestnut et al, 1999; Cicerone et al, 2002).

Apart from the variability of rehabilitation processes, comparisons between studies are also difficult because of the heterogeneity of participant within programmes. A previous systematic review on community integration following brain injury (Reisetter and Abreu, 2005) demonstrated that community integration was mediated by severity of injury, age, gender, education, prior work, living environment, cognition, emotional status, functional performance and disability. These factors make the process of interpreting the results of systematic reviews to decide on effective interventions difficult (Bennett and Bennett, 2000). There is perhaps more value in replicating programmes in different contexts to compare results across different client groups within the TBI population. Alternatively future research and programme design may be aimed at identify gaps in service as perceived by the client population. The finding of Powell et al (2002: p.201) that people with longer-standing severe brain injuries 'tended to make greater gains' provides some support to the usefulness 
of community rehabilitation for people following TBI.

The systematic review of previous studies reminds me of my fascination for shell collecting; a process that took many hours of my childhood holidays and continues to this day. As you search the beach for the best and most beautiful shells, sifting through sands and pebbles, digging down to find the treasures that others have perhaps missed, you become absorbed with appraising each item. In this review the search resulted in 878 articles that were organized and evaluated, those that did not meet the criteria being discarded until eleven studies were identified. The critical appraisal of each of the studies and the synthesis of the collected results aims to ensure that what you end up with is the best of the best. The point of this analogy, if you will bear with me, is that in this truly valuable process we risk losing sight of the long dead inhabitant of the shell, the reason why the shell exists and the environment in which the shell dweller survived. In the same way systematic reviews are distant from the individual people for whom the rehabilitation was designed.

In essence the outcome of this review is useful to allied health professional and service providers in planning the design of future rehabilitation programmes, provided that the programmes are specifically aimed to meet the needs of the clients. The long-term consequences of $\mathrm{TBI}$ can be devastating for the individuals and their families. Psychosocial issues are perhaps the most disabling and have the greatest impact on interpersonal relations and community integration. The relationship between person, place and environment is complex and linear thinking in relation to rehabilitation undermines the integration of factors that can enhance quality of life outcomes. The focus of this review is quality of life and daily functioning, and the aim is to demonstrate the most effective interventions in an attempt to guide future service design. In fact, it provides a snap shot of the current level of knowledge and highlights the need to explore and develop alternative rehabilitation interventions in the future.

There is potential to extend the telephone counselling concept to include a greater use of web-based technology including on-line forums and real time chat rooms. Information technology provides a range of new options for peer support that can include carers and families through the use of Facebook and similar Web 2.0 technology. Client-centred and family-centred interventions that include the participatory action by people with TBI in the design and the facilitation could be developed, targeted to meet the expressed needs of service users. The optimal outcome of community rehabilitation is integration and participation and therefore the framework of the International Classification of Function (ICF) offers an alternative model for measuring the outcome of programmes.

Rehabilitation professionals involved in such community rehabilitation programmes need to focus on meaningful outcomes that make a difference to the lived experience of clients and their carers, ensuring a focus on functioning in the community and improving life satisfaction.

Bennett S, Bennett J (2000) The process of evidence-based practice in occupational therapy: Informing clinical decision. Australian Occupational Therapy Journal 47: 171-80

Carney N, Chestnut R, Maynard H, Mann N, Patterson P, Helfand M (1999) Effect of cognitive rehabilitation on outcomes for persons with traumatic brain injury: A systematic review. I Head Trauma Rehabil 14(3): 277-307

Chestnut R, Carney N, Maynard H, Mann N, Patterson P, Hlefand M (1999) Evidence for the effectiveness of rehabilitation for persons with traumatic brain injury. $J$ Head Trauma Rehabil 14(2): 176-88

Cicerone K, Dahlberg C, Malec J et al (2002) Evidence-based cognitive rehabilitation: Updated review of the literature from 1998-2002. Arch Phys Med Rehabil 8: 1681-92

Powell J, Heslin J, Greenwood R (2002) Community based rehabilitation after severe traumatic brain injury: A randomised controlled trial. I Neurol Neurosurg Psychiatry 72(2): 193-202

Reisetter T, Abreu B (2005) Appraising the evidence on community integration following brain injury: A systematic review. Occup Ther Int 12(3): 196-217

\section{Yvonne Thomas}

Senior Lecturer

Occupational Therapy,

James Cook University,

Townsville,

Queensland, Australia 